\title{
Role of Serum Midkine Level as a Diagnostic Biomarker for Very Early and Early Hepatocellular Carcinoma
}

\author{
Maysaa Abdallah Saeed ${ }^{1}$, Ibrahim M. Ibrahim ${ }^{1}$ and Amal Ahmed Zidan \\ ${ }^{1}$ Tropical Medicine Department, Faculty of Medicine, Zagazig University, Zagazig, Egypt \\ ${ }^{2}$ Clinical Pathology Department, Faculty of Medicine, Zagazig University, Zagazig, Egypt
}

Corresponding Author Ibrahim M. Ibrahim

Mobile: 01225771945

E mail: Ibrahimibrahim1979@ yahoo. com

Key words: Serum midkine, very early and early $\mathrm{HCC}$ and $A F P$ negative $\mathrm{HCC}$
Background and study aim: AFP is the most commonly utilized biomarker for HCC although it has a low sensitivity and specificity for the disease. New biomarkers with better sensitivity and specificity are to be studied. The aim of this work is to evaluate the role of midkine as a biomarker for early detection of HCC and for detection of HCC in patients negative for AFP.

Patients and Methods: This study included 46 HCC patients on top of Child Pugh class A cirrhosis (group A), 46 patients with Child Pugh class A cirrhosis without liver focal lesion(s) (group B) and 46 apparently healthy controls (group C). Demographics, clinical data, radiologic findings, biochemical profile including

\section{INTRODUCTION}

Hepatocellular carcinoma (HCC) is the second leading cause of malignancy related mortality all over the world with incidence rising both in the USA and abroad [1]. Globally, there are nearly 700,000 new cases of HCC reported each year. Studies show that the incidence rate continues to approximate the death rate indicating that most of the patients who develop HCC die from it. Fiveyear survival rates in the USA have modestly improved to approximately 26\%. This improvement can be attributed to the advanced surveillance in identifiable high-risk groups (eg, patients of chronic infection with hepatitis $\mathrm{B}$ and $\mathrm{C}$ viruses) and to the improvement in surgical intervention (resection or transplantation) for patients with early stage disease [2].

According to the revised version of Barcelona Clinic for Liver Cancer (BCLC) system released by the serum AFP and midkine assessment using specific ELISA tests of the study participants were entered in the study.

Results: Serum midkine had a statistically significant better sensitivity, specificity, positive predictive value, negative predictive value and accuracy over serum AFP for diagnosing very early and early HCC from liver cirrhosis and for diagnosing AFP negative $\mathrm{HCC}$ from liver cirrhosis.

Conclusion: Serum midkine is to be considered for diagnosis of very early and early HCC especially in AFP negative cases.

American Association for the Study of Liver Diseases (AASLD) [3], HCC is defined as very early when one nodule smaller than $2 \mathrm{~cm}$ is present in a cirrhotic liver Child-Pugh class A with no symptoms and no change in the performance status. Early HCC is defined when one nodule smaller than $5 \mathrm{~cm}$ or up to 3 nodules smaller than 3 $\mathrm{cm}$ each is/are present in a cirrhotic liver Child-Pugh class A or B with no symptoms and no change in the performance status.

$\mathrm{HCC}$ incidence is increasing in Egypt. The current increase in incidence of HCC among Egyptians may be due to the $\mathrm{HCV}$ epidemic in the last 3 decades in Egypt. HCV is regarded as a primary risk factor for HCC among Egyptians [4]. HCC is the second most frequent cause of malignancy incidence and mortality among Egyptian men after bronchogenic carcinoma [5]. 
Although histopathologic evaluation of a tumor biopsy is considered the gold standard for establishing the diagnosis of HCC, it is considered an invasive technique with a high risk of seedling of tumor cells along the biopsy track [6]. As regard serologic screening, AFP still represents the most commonly utilized test for HCC although it has a sensitivity of 39 to $65 \%$ and there is a high rate of false negative and false positive results [7]. Many studies showed that des- $\gamma$-carboxyprothrombin and AFP-L3 were not of better sensitivity nor specificity for diagnosis of early HCC [8]. This highlights the need for new more reliable non-invasive biomarkers with better sensitivity and specificity for the early diagnosis of HCC and for diagnosis of AFP negative $\mathrm{HCC}$.

Midkine (MDK) - also known as neurite growth promoting factor 2 (NEGF2) - is a basic heparin binding growth factor of low molecular weight. In humans, it is encoded by the MDK gene on chromosome 11 [9]. It is a developmentally important retinoic acid responsive gene product strongly induced during the mid gestation; hence the name midkine. Expression of the MDK gene in human adult tissues is extremely low and restricted. Different studies showed that MDK plays a significant role in carcinogenesis-related activities including proliferation, migration, antiapoptosis, mitogenesis, transformation and angiogenesis in many types of solid tumors including hepatocellular carcinoma [10]. The clinical utility of serum MDK evaluation has been previously studied in pancreatic cancer [11], neuroblastoma [12], oral squamous cell carcinoma [13], esophageal squamous cell carcinoma [14] and breast cancer [15].

In the present study, we aimed at investigating the diagnostic utility of serum MDK evaluation as a biomarker for very early and early HCC and especially for AFP negative cases.

\section{PATIENTS AND METHODS}

This is a case-control study that included 46 patients diagnosed with HCC (37 males and 9 females with age in the range of 45-88 years) as the case group and 46 cirrhotic patients (34 males and 12 females with age in the range of 45-80 years) as the disease control group. All these patients were admitted to Tropical Medicine Department affiliated to Zagazig university hospitals in the period from June, 2016 to February, 2017.
Also, 46 healthy subjects selected from patients' relatives (32 males and 14 females with age in the range of 44-87 years) were included and represented the healthy control group.

All study participants exhibited good compliance and provided a written consent to be included. Patients with HCC and naïve to treatment (diagnosed by triphasic CT criteria and / or by histopathology according to AASLD guidelines) were included in group (A). Cirrhotic patients with no evidence of hepatic focal mass(es) in ultrasound evaluation were included in group (B). Diagnosis of liver cirrhosis was based on clinical, laboratory and imaging studies. All patients included in groups A and B were ChildPugh class A. Healthy controls included in group (C) were selected from patients' relatives and were free from any clinical, laboratory and sonographic abnormalities.

Patients who had any malignancy other than HCC, those who had a history of intravenous administration of heparin prior to evaluation of their serum midkine by 48 hours, those who had rheumatoid arthritis, Child-Pugh classes B and C cirrhotic patients and those having end stage major organ disease were excluded from the study.

All participants were subjected to history taking, thorough clinical examination and laboratory investigations in the form of complete blood count, liver function tests, kidney function tests, coagulation profile, viral markers (HCV Ab and HBsAg) and alpha fetoprotein assessment. These investigations were done by the conventional methods used.

Midkine assessment was done for all participants. The assay was performed using enzyme-linked immunosorbent assay (ELISA) kits supplied by Glory Science (Glory Science Co., Ltd, 2400 Veterans Blvd. Suite 16- 101, Del Rio, TX 78840, USA).

Imaging studies were performed for all patients. Pelviabdominal ultrasonography using sonoscape c11 was done. The liver was examined for its size, surface, echogenicity and hepatic viens. The portal vein diameter and splenic axis were measured. A special emphasis regarding the HCC masses was done including their number, site, size, echogenicity and any special character.

Triphasic computed tomography (CT) with contrast of the liver was performed for patients with hepatic focal lesion(s) in ultrasonography.The 
diagnostic character of $\mathrm{HCC}$ on contrastenhanced CT is arterial hypervascularity with washout of intra-lesional contrast in portal venous and delayed phase images [16].

Data were checked, entered and analyzed through Epi-Info (2000) for data processing and statistics. Data were expressed as numbers and percentages for qualitative variables and mean, standard deviation, median and interquartile range for non parametric quantitative data.
Comparison of means was done using standard (t) test, Mann-Whitney test, one way ANOVA (f test), Kruskal Wallis test and Chi-square test $\left(\mathrm{X}^{2}\right)$. Validity of a screening test was expressed as sensitivity, specificity, positive predictive value, negative predictive value and accuracy. For all these statistical tests used, the threshold of significance was fixed at 5\% level (P-value). The smaller the P-value obtained, the more significant were the results.

\section{RESULTS}

Table (1): Criteria of hepatic focal lesion(s) in group A

\begin{tabular}{|l|c|c|}
\hline \multirow{2}{*}{ Criteria of hepatic focal lesions } & \multicolumn{2}{|c|}{$\begin{array}{c}\text { Group A } \\
\text { (HCC patients) } \\
\text { (n=46) }\end{array}$} \\
\cline { 2 - 3 } & No & \% \\
\hline Number of focal lesion & 39 & 84.78 \\
\hline Single & 7 & 15.22 \\
\hline Multiple & \multicolumn{3}{|c|}{} \\
\hline Size of focal lesion & 17 & 36.95 \\
\hline$\leq 2 \mathrm{~cm}$ & 29 & 63.05 \\
\hline $2-5 \mathrm{~cm}$ & \multicolumn{3}{|}{} \\
\hline Portal vein thrombosis & 46 & 100 \\
\hline No & 0 & 0 \\
\hline Yes & \multicolumn{2}{|c|}{} \\
\hline
\end{tabular}

Table (2): Serum AFP and midkine levels among the studied groups

\begin{tabular}{|c|c|c|c|c|c|c|c|}
\hline $\begin{array}{c}\text { Tumor } \\
\text { markers }\end{array}$ & $\begin{array}{c}\text { Group A } \\
\begin{array}{c}\text { HCC patients) } \\
(n=46)\end{array} \\
\end{array}$ & $\begin{array}{c}\text { Group B } \\
\begin{array}{c}\text { (Liver cirrhosis) } \\
(n=46)\end{array} \\
\end{array}$ & $\begin{array}{c}\text { Group C } \\
\text { (Control group) } \\
(n=46) \\
\end{array}$ & Test & P1 & $\mathbf{P 2}$ & P3 \\
\hline \multicolumn{8}{|l|}{ AFP (ng/ml) } \\
\hline Median & 91 & 16.4 & 1.9 & \multirow{3}{*}{$\begin{array}{c}\text { Kruskall } \\
\text { Wallis } \\
73.4\end{array}$} & \multirow{3}{*}{0.02} & \multirow{3}{*}{0.00} & \multirow{3}{*}{0.00} \\
\hline Range & $1.1-761$ & $9.4-23$ & $1.6-2.2$ & & & & \\
\hline Q1-Q2 & $7.3-404$ & $12.5-18.5$ & $1.8-2.08$ & & & & \\
\hline \multicolumn{8}{|c|}{ Midkine (ng/dl) } \\
\hline Mean \pm SD & $62.6 \pm 26$ & $25.8 \pm 9.9$ & $19.1 \pm 4.2$ & \multirow{2}{*}{$\mathrm{F}=93.5$} & \multirow{2}{*}{0.00} & \multirow{2}{*}{0.00} & \multirow{2}{*}{0.00} \\
\hline Range & $22-165$ & $15-75$ & $0-0.6$ & & & & \\
\hline
\end{tabular}

$\mathrm{P} 1$ denotes $\mathrm{p}$ value of significance test comparing between groups $\mathrm{A}$ and $\mathrm{B}$.

$\mathrm{P} 2$ denotes $\mathrm{p}$ value of significance test comparing between groups $\mathrm{A}$ and $\mathrm{C}$.

$\mathrm{P} 3$ denotes $\mathrm{p}$ value of significance test comparing between groups $\mathrm{B}$ and $\mathrm{C}$. 
Table (3): Diagnostic performance of the best cut off values of midkine and AFP in detecting HCC versus non hepatocellular carcinoma controls

\begin{tabular}{|c|c|c|c|c|c|c|c|c|}
\hline & 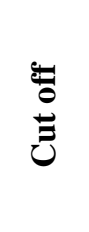 & $\begin{array}{l}\overline{0} \\
0 \\
0 \\
0 \\
0 \\
2\end{array}$ & 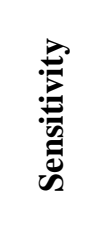 & 总 & 离 & 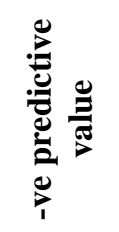 & 冚 & 2 \\
\hline $\begin{array}{l}\text { Midkine } \\
\text { (ng/dL) }\end{array}$ & 34 & $\begin{array}{c}0.94 \\
(0.90-0.99)\end{array}$ & $91 \%$ & $90 \%$ & $89.3 \%$ & & $91.1 \%$ & 0.00 \\
\hline $\begin{array}{l}\text { AFP } \\
(\mathrm{ng} / \mathrm{mL})\end{array}$ & 21.5 & $\begin{array}{c}0.63 \\
(0.5-0.7)\end{array}$ & $56 \%$ & $90 \%$ & $81.2 \%$ & $66.6 \%$ & 71 & 0.02 \\
\hline
\end{tabular}

Table (4): Diagnostic performance of the best cut off values of midkine and AFP in detecting very early HCC $(\leq 2 \mathrm{~cm})$ versus non hepatocellular carcinoma controls

\begin{tabular}{|c|c|c|c|c|c|c|c|c|}
\hline & 苛 & 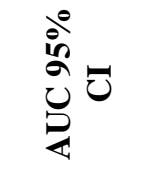 & 总 & 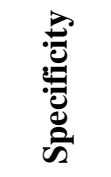 & 苞 & 离 & 冚 & a \\
\hline $\begin{array}{l}\text { Midkine } \\
\text { (ng/dL) }\end{array}$ & 32 & $\begin{array}{c}0.8 \\
(0.7-0.9) \\
\end{array}$ & $94 \%$ & $91.3 \%$ & $66.6 \%$ & $98.8 \%$ & 91 & 0.00 \\
\hline $\begin{array}{l}\text { AFP } \\
\text { (ng/mL) }\end{array}$ & 18.5 & $\begin{array}{c}0.7 \\
(0.5-0.8) \\
\end{array}$ & $70 \%$ & $86 \%$ & $50 \%$ & $94 \%$ & 84 & 0.00 \\
\hline
\end{tabular}

Table (5): Diagnostic performance of the best cut off values of midkine and AFP in detecting early HCC $(2-5 \mathrm{~cm})$ versus non hepatocellular carcinoma controls

\begin{tabular}{|c|c|c|c|c|c|c|c|c|}
\hline & 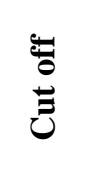 & 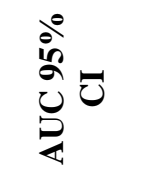 & 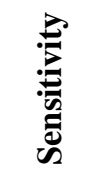 & 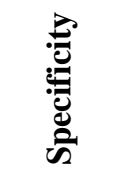 & 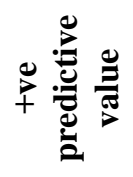 & 胥 & 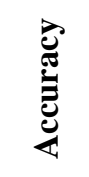 & a \\
\hline $\begin{array}{l}\text { Midkine } \\
\text { (ng/dL) }\end{array}$ & 27.5 & $\begin{array}{c}0.9 \\
(0.8-0.9)\end{array}$ & $96 \%$ & $82.6 \%$ & $73.3 \%$ & $98.7 \%$ & 87.6 & 0.00 \\
\hline $\begin{array}{l}\text { AFP } \\
(\mathrm{ng} / \mathrm{mL})\end{array}$ & 19.5 & $\begin{array}{c}0.6 \\
(0.5-0.8) \\
\end{array}$ & $50 \%$ & $80 \%$ & $76.4 \%$ & $94.2 \%$ & 89.8 & 0.00 \\
\hline
\end{tabular}

Table (6): Diagnostic performance of the best cut off values of midkine in HCC with AFP-negative $(<20 \mathrm{ng} / \mathrm{mL})$ from non hepatocellular carcinoma controls

\begin{tabular}{|c|c|c|c|c|c|c|c|c|}
\hline & 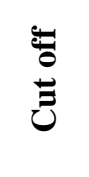 & 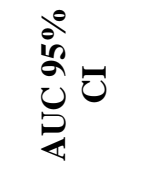 & 吝 & 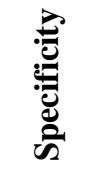 & 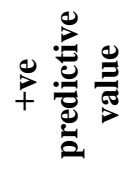 & 莺 & 异 & 2 \\
\hline $\begin{array}{l}\text { Midkine } \\
\text { (ng/dL) }\end{array}$ & 36.5 & $\begin{array}{c}0.934 \\
(0.8-0.9) \\
\end{array}$ & $85 \%$ & $88 \%$ & $77 \%$ & $92 \%$ & $78.7 \%$ & 0.00 \\
\hline
\end{tabular}


Table (7): Comparison between HCC patients negative for AFP $(<20 \mathrm{ng} / \mathrm{mL})$ and HCC patients positive for AFP as regard to midkine level

\begin{tabular}{|l|c|c|c|c|}
\hline & $\begin{array}{c}\text { HCC (low or negative AFP) } \\
\text { N=20 }\end{array}$ & $\begin{array}{c}\text { HCC(high AFP) } \\
\mathbf{N = 2 6}\end{array}$ & T & P \\
\hline Midkine (ng/dL) & $46 \pm 10.9$ & $75 \pm 28$ & 4.7 & 0.000 \\
\hline Mean \pm SD & $38-56$ & $62.5-83.5$ & & \\
\hline Q1-Q3 &
\end{tabular}

\section{DISCUSSION}

AFP is the only serologic biomarker commonly utilized for diagnosis of HCC. However, its sensitivity is still limited (39-65\%); especially in small well-differentiated HCC. In addition, false positive levels of AFP were as high as $40 \%$ [17]. The normal range for serum AFP is $10-20 \mathrm{ng} / \mathrm{ml}$ and a value more than $200 \mathrm{ng} / \mathrm{ml}$ is usually regarded as of diagnostic index. However, up to $65 \%$ of HCC patients with a nodule smaller than $5 \mathrm{~cm}$ in diameter have serum AFP less than 200 $\mathrm{ng} / \mathrm{ml}$ and up to $20 \%$ of HCC masses do not secrete AFP [18]. Therefore, the lack of AFP sensitivity and specificity has promoted research for new tumor biomarkers for differentiating HCC from benign hepatic lesions [19].

The aim of this study was to assess the role of serum midkine measurement as a non-invasive biomarker for diagnosis of very early, early and AFP negative HCC.

The present study was conducted on 138 subjects divided into 3 groups; 46 patients with $\mathrm{HCC}$ as group A, 46 cirrhotic patients as group B and 46 apparently healthy control subjects as group C. All patients were matched as regard age, gender and residence. Child Pugh class A patients were included in the study while Child Pugh classes B and $\mathrm{C}$ were excluded. Patients with $\mathrm{HCC}$ were of very early and early stages of the disease. Advanced stage of HCC and cases with portal vein thrombosis were excluded from the study.

Our results revealed a significantly higher level of AFP in HCC group (median $=91 \mathrm{ng} / \mathrm{mL}$ ) and chronic liver disease group (median $=16.4$ $\mathrm{ng} / \mathrm{mL}$ ) compared to the control group (median= $1.9 \mathrm{ng} / \mathrm{mL}$ ). In addition, AFP values were significantly higher in $\mathrm{HCC}$ patients compared to chronic liver disease patients. This was in agreement with Wei et al. [20] and Othman et al. [21] who found that AFP increases in chronic liver disease patients and also proved that AFP increases significantly in HCC patients than in chronic liver disease patients.
In this study, there was a highly significant statistical difference between the mean value of serum MDK levels in patients with HCC compared to patients with liver cirrhosis and the healthy controls with mean \pm SD values of 62.6 $\pm 26,25.8 \pm 9.9$ and $19.1 \pm 4.2 \mathrm{ng} / \mathrm{dL}$ respectively $(\mathrm{p}<0.001)$. These findings are in agreement with those of Zhu et al. [22] who found that serum MDK was significantly elevated among HCC patients when compared with chronic liver disease patients and healthy individuals.

In the present study, MDK had sensitivity of $91 \%$ and specificity of $90 \%$ for detection of HCC at the optimal cut off value of $34 \mathrm{ng} / \mathrm{dL}$ with AUC of 0.94 when compared with liver cirrhosis while AFP had sensitivity of $56 \%$ and specificity of $90 \%$ at the optimal cut off value of 21.5 $\mathrm{ng} / \mathrm{mL}$ with AUC of 0.63 when compared with liver cirrhosis. These results are similar to those of Karim et al. [23] who found that MDK and AFP had sensitivities of (92.5\% versus $40 \%)$, specificities of (83.3\% versus $96.7 \%)$ respectively. Through the analysis of the ROC curve, they found that the AUC (0.941) for serum MDK was larger than that of serum AFP (0.671).

On the contrary of the previous results, Hung et al. [24] found that at cut off value of $50 \mathrm{ng} / \mathrm{dL}$, MDK had sensitivity of $51 \%$ and specificity of $60 \%$. This difference in results can be attributed to difference in the studied population and the number of patients included in both studies. Patients included in that study had HCC complicating HBV induced liver cirrhosis and were of advanced stage of HCC while most of the patients in this study were HCC complicating $\mathrm{HCV}$ induced liver cirrhosis and all of them were of very early and early stages of the disease.

The best cutoff values for MDK and AFP to discriminate very early $\mathrm{HCC} \leq 2 \mathrm{~cm}$ from nonhepatocellular carcinoma controls (liver cirrhosis patients and healthy controls) were $32 \mathrm{ng} / \mathrm{dL}$ and $18.5 \mathrm{ng} / \mathrm{mL}$ respectively; with sensitivities of $94 \%$ versus $70 \%$ and specificities of $91.3 \%$ versus $86 \%$. The AUC was 0.8 for serum MDK 
and was found to be larger than that of serum AFP (0.7) with a highly significant statistical difference $(\mathrm{P}<0.001)$. While the best cutoff values for MDK and AFP to discriminate early HCC 2-5 cm in diameter from non-hepatocellular carcinoma controls (liver cirrhosis patients and the healthy controls) were $27.5 \mathrm{ng} / \mathrm{dL}$ and 19.5 $\mathrm{ng} / \mathrm{mL}$ respectively; with sensitivities of $96 \%$ versus $50 \%$ and specificities of $82.6 \%$ versus $80 \%$. The AUC was 0.9 for MDK and was found to be much larger than that of AFP (0.6) with highly significant statistical difference $(\mathrm{P}<0.001)$. This means that the overall diagnostic performance of serum MDK for diagnosis of very early HCC $\leq 2 \mathrm{~cm}$ and early $\mathrm{HCC} 2-5 \mathrm{~cm}$ in diameter is much better than that of serum AFP. This is in agreement with Zhu et al. [22] who reported that serum MDK had a better performance compared with AFP for distinguishing very early hepatocellular carcinoma as well as early hepatocellular carcinoma from liver cirrhosis and healthy controls.

In this study, there was highly significant statistical difference between mean value of serum MDK in HCC patients negative for AFP (values $<20 \mathrm{ng} / \mathrm{mL}$ ) compared to HCC patients positive for AFP (values $>20 \mathrm{ng} / \mathrm{mL}$ ) with mean $\pm \mathrm{SD}$ values of $46 \pm 10.9$ and $75 \pm 28 \mathrm{ng} / \mathrm{dL}$ respectively $(\mathrm{p}<0.001)$. Diagnostic performance of serum MDK in discriminating HCC negative for AFP from liver cirrhosis and healthy controls revealed that serum MDK at a cut off value of $36.5 \mathrm{ng} / \mathrm{dL}$ showed sensitivity of $85 \%$, specificity of $88 \%$, PPV of $77 \%$, NPV of $92 \%$ and AUC of $0.934(\mathrm{p}<0.001)$. These results agree with results obtained by Zhu et al. [16] who reported that serum MDK had a good performance for distinguishing AFP-negative hepatocellular carcinomas from non-hepatocellular carcinoma controls with AUC 0.926.

Finally, this study revealed that assessment of serum MDK is to be used as a non-invasive marker for detection of HCC patients complicating chronic hepatitis $\mathrm{C}$ with very early and early disease stages and/or negative for AFP.

\section{Funding: None.}

\section{Conflicts of interest: None.}

Ethical Approval:Approved

\section{REFERENCES}

1- Siegel R, Naishadham D and Jemal A. Cancer statistics. CA Cancer J Clin; 2012; 62(1): 10-29.
2- Jemal A, Bray F and Center M. Global cancer statistics. Role of areca nut in betel quid-associated chemical carcinogenesis: current awareness and future perspectives. Oral Oncol.; 2011; 37:477492.

3- Bruix J and Sherman M. Management of hepatocellular carcinoma. Hepatolog, 2005; 42 (5): 1208-1236.

4- El-Zayadi A, Badran HM and Barakat EM. Hepatocellular carcinoma in Egypt:A single center study over a decade. World J. Gastroenterol.; 2005; 11(33): 5193-5198.

5- Freedman LS, Edwards BK and Ries LA. Cancer incidence in four member countries (Cyprus, Egypt, Israel, and Jordan) of the middle east cancer consortium (MECC) compared with US SEER. Bethesda: National Cancer Institute; Available in: http://seer.cancer.gov/publications/mecc/ mecc_ monograph.pdf, 2006.

6- Gomaa A, Khan SA and Toledano MB. Hepatocellular carcinoma: Epidemiology, risk factors and pathogenesis. World J Gastroenterol; 2009; $14: 4300$.

7- Shariff M, Cox IJ, Gomaa AI, Khan SA, Gedroyc $\mathrm{W}$ and Taylor-Robinson SD. Hepatocellular carcinoma: current trends in worldwide epidemiology, risk factors, diagnosis and therapeutics. Expert Rev. Gastroenterol. Hepatol.; 2009; 3: 353-367.

8- Marrero JA and Welling T. Modern diagnosis and management of hepatocellular carcinoma. Clin Liver Dis; 2009; 13(2): 233-47.

9- Ibusuki M, Fujimori H, Yamamoto Y, Ota K, Ueda M, Shinriki S, Taketomi M, Sakuma S, Shinohara $\mathrm{M}$, Iwase $\mathrm{H}$ and Ando $\mathrm{Y}$. Midkine in plasma as a novel breast cancer marker. Official Journal of Japanese Cancer Association (JCA.); 2009; 100(9): 1735-1739.

10- Muramatsu T. Midkine and pleiotrophin: two related proteins involved in development, survival, inflammation and tumorigenesis. J. Biochem. (Tokyo), 2002; 132 (3): 359-71.

11- Ohhashi S, Ohuchida K, Mizumoto K, Egami T, Yu J, Cui L, Toma H, Takahata S, Nabae T and Tanaka M. Midkine mRNA is over-expressed in pancreatic cancer. Dig. Dis. Sci.; 2009; 54: 811-815.

12- Ikematsu S, Nakagawara A, Nakamura Y, Ohira M, Shinjo M, Kishida S and Kadomatsu K. Plasma midkine level is a prognostic factor for human neuroblastoma. Cancer Sci.; 2008; 99: 2070-2074.

13- Ota K, Fujimori H, Ueda M, Shiniriki S, Kudo M, Jono $\mathrm{H}$ et al. Midkine as a prognostic biomarker in oral squamous cell carcinoma. Br. J. Cancer; 2008; 99: 655-662. 
14- Shimada H, Nabeya Y, Tagawa M, Okazumi S, Matsubara H, Kadomatsu $\mathrm{K}$ et al. Preoperative serum midkine concentration is a prognostic marker for esophageal squamous cell carcinoma. Cancer Sci.; 2003; 94: 628-632.

15- Ibusuki M, Fujimori H, Yamamoto Y, Ota K, Ueda $\mathrm{M}$, Shinriki $\mathrm{S}$ et al. Midkine in plasma as a novel breast cancer marker. Official Journal of Japanese Cancer Association (JCA.); 2009; 100(9): 17351739.

16- Ghanaati H, Alavian S, Firouznia K, Abedini MR, Mohammadifard M, Jalali AH et al. Tailoring of Interventional Procedures for HCC Patients-Review Article. Iran J Radiol.; 2010; 7(3) :129-43.

17- Bertino G, Neri S, Bruno CM, Ardiri AM, Calvagno GS, Malaguarnera $\mathrm{M}$, et al. Diagnostic and prognostic value of alpha-fetoprotein, des- $\gamma$ carboxy prothrombin and squamous cell carcinoma antigen immunoglobulin Mcomplexes in hepatocellular carcinoma. Minerva Med; 2011; 102(5): 363-71.

18- Toyoda H, Kumada T, Osaki Y, Oka H and Kudo M. Role of tumor markers in assessment of tumor progression and prediction of outcomes in patients with hepatocellular carcinoma. Hepatol Res; 2007; 37 (Suppl 2): S166-S171.
19- Zhao YJ, Ju Q and Li GC. Tumour markers for hepatocellular carcinoma. Mol Clin Oncol; 2013; 1(4): 593-8.

20- Wei W, Deng FY, Tong MY, Ji WF and Xiu FL. Combined Serum hepatoma-specific alpha fetoprotein and circulating alpha fetoproteinmRNA in diagnosis of hepatocellular carcinoma. Hepatobiliary Pancreatic Dis. Int.; 2006; 5: 538544.

21- Othman M, Aref A, Mohamed A and Ibrahim W. Serum Levels of Interleukin-6 and Interleukin-10 as Biomarkers for Hepatocellular Carcinoma in Egyptian Patients ISRN Hepatology; 2013; ID 412317: 9.

22- Zhu WW, Guo JJ, Guo L, Jia HL, Zhu M, Zhang $\mathrm{JB}$ et al. Evaluation of midkine as a diagnostic serum biomarker in hepatocellular carcinoma. Clin Cancer Res. 2013; 19(14):3944-54.

23- Karim YA, Abeer IA, Eslam S and Ashraf MA. The value of serum midkine level in diagnosis of hepatocellular carcinoma. Int J Hepatol.; 2015; 2015: 146389.

24- Hung YJ, Lin ZH, Cheng TI, Liang CT, Kuo TM and Kao KJ. Serum midkine as a prognostic biomarker for patients with hepatocellular carcinoma. Am J ClinPathol; 2011; 136(4):594603. 